\title{
Papan Informasi Berbasis Web Server Controlled HTTP Requests di STMIK AUB Surakarta
}

\author{
Widyo Ari Utomo ${ }^{1}$, Ernes Cahyo Nugroho ${ }^{2}$, Dhantel Rhesa Praweda ${ }^{3}$, Sidik Purnomo ${ }^{4}$ \\ ${ }^{1234}$ Program Studi Sistem Komputer, STMIK AUB, Surakarta, Indonesia \\ e-mail:*1widyo.ari@stmik-aub.ac.id, 2ernes.cahyo@stmik-aub.ac.id, ${ }^{3}$ dhantel@stmik-aub.ac.id, \\ ${ }^{4}$ sidikpurnomo1504@gmail.com
}

\begin{abstract}
Abstrak
Informasi merupakan suatu hal yang tidak dapat lepas dari kebutuhan manusia. Media informasi saat ini semakin beragam, mulai dari media cetak hingga elektronik. Running text merupakan salah satu media elektronik yang digunakan untuk menampilkan informasi kepada publik dengan bantuan LED (Light Emitting Dioda). Informasi yang ditampilkan dapat berupa pengumuman, berita, dan informasi lainya. Informasi yang ditampilkan dalam running text tersebut sebisa mungkin adalah informasi terbaru. Untuk itu diperlukan media yang dapat mengganti informasi pada running text kapan saja, dimana saja tanpa terkendala jarak dan waktu. Berdasarkan masalah yang ada solusi pada penelitian ini membuat papan informasi berbasis web server controlled HTTP requests di STMIK AUB Surakarta. Papan informasi menggunakan perangkat running text sebagai penampil informasi dengan bantuan mikrokontroler arduino uno. Informasi pada running text diperbarui melalui sebuah webserver yang dibuat khusus untuk mengupdate. Informasi pada webserver kemudian dikirim, lalu ethernet shield yang telah terpasang dengan arduino uno menerima data dan arduino uno mengolahnya untuk kemudian data tersebut ditampilkan pada running text. Hasil pengujian memperlihatkan bahwa papan informasi dengan data berbasis webserver dapat berjalan dengan baik. Setiap informasi yang diinputkan berhasil dimunculkan pada perangkat running text. Papan informasi mampu menampilkan 80 karakter sehingga konten dari informasi yang ingin disampaikan dapat maksimal dan di mengerti.
\end{abstract}

Kata kunci: Running text, Arduino uno, Ethernet shield, Webserver, HTTP requests

\section{PENDAHULUAN}

Informasi merupakan suatu hal yang tidak dapat lepas dari kebutuhan manusia, baik itu informasi secara lisan, tulisan, gambar maupun video. Semakin berkembangnya teknologi informasi, media yang digunakan untuk menyampaikan informasi saat ini semakin beragam. Mulai dari media cetak hingga elektronik. Media informasi elektronik menggunakan LED (Light Emitting Diode) display saat ini sudah semakin sering digunakan, dengan berbagai macam tujuan, dari penunjuk jalan, periklanan, pengumuman, berita, hingga informasi lainnya. Running text merupakan salah satu media untuk menampilkan informasi kepada publik menggunakan LED (Light Emitting Diode). Running text terdiri dari serangkaian LED (Light Emitting Diode) yang tersusun secara matriks yang diprogram sehingga dapat menuliskan karakter yang diinginkan.

Informasi yang di tampilkan running text berupa tulisan berjalan yang menarik perhatian dengan memuat banyak konten (tulisan) dan animasi yang menarik. Dengan menggunakan running text, informasi yang tawarkan terlihat menarik karena tampilan warna yang cerah dan bentuk tulisan yang bisa diatur gerakannya. Bandingkan dengan papan merek atau spanduk yang tampilannya statis atau diam serta isinya hanya itu-itu saja dari hari ke hari

Received November 11, 2019; Revised November 25, 2019; Accepted December 9, 2019 
belum lagi jika warna dari spanduk atau plang merek tersebut sudah agak memudar, hampir bisa dipastikan orang tidak akan meliriknya lagi.

STMIK AUB Surakarta (Sekolah Tinggi Manajemen Informatika Dan Komputer Adi Unggul Bhirawa) adalah sebuah perguruan tinggi swasta yang terletak di JL. MW. Maramis No.29, Nusukan, Banjarsari, Kota Surakarta, Jawa Tengah. STMIK AUB Surakarta telah menggunakan running text untuk informasi jadwal laboratorium komputer yang telah dibuat oleh widodo dan Muthohir (2014) sebagai karya kerja praktek. Informasi pada running text yang digunakan masih bersifat statis sehingga informasi yang di tampilkan hanya jadwal laboratorium komputer. Perubahan jadwal pada running text dilakukan dengan mengubah coding yang tertanam pada mikrokontroler. Penggantian coding menggunakan Compiler Integrated Development Environment (IDE) arduino v1.0.5. Hal tersebut mengharuskan, penguna running text jika ingin memperbarui informasi, maka ia harus menghubungkan perangkat running text tersebut dengan komputer melalui konektor serial maupun konektor USB.

Kebutuhan akan kecepatan dan kemudahan dalam memperbarui informasi sangat perlu untuk ditingkatkan. Seperti memperbarui informasi running text yang dapat dilakukan dari jarak jauh, dimanapun dan kapanpun tanpa harus berada dekat dengan running text. Sehingga diharapkan dapat mempermudah mahasiswa dalam mendapatkan informasi secacara cepat dan akurat. Website merupakan salah satu sarana penyampai informasi yang umum digunakan pada saat ini. Kemudahan mengakses sebuah website sudah didukung meluasnya jaringan internet. Mengintegrasikan aplikasi website dengan perangkat mikrokontroler, tugas-tugas pengendalian atau monitoring sebuah alat elektronik sudah dapat dilakukan.

Berdasarkan masalah yang ada mendorong penulis mengembangkan display jadwal laboratorium STMIK AUB Surakarta dengan merancang sebuah media informasi menggunakan LED disusun dalam bentuk matriks, yang dapat dikendalikan melalui sebuah web server dengan memanfaatkan komunikasi serial antara server dan mikrokontroler. Dimana semua informasi yang akan ditampilkan dapat diperbaharui secara realtime melalui sebuah web portal yang berfungsi sebagai antarmuka sistem. Sehingga apabila ada informasi baru bisa segera diinformasikan ke mahasiswa melalui running text. Untuk selanjutnya dalam penyusunan Skripsi ini penulis menyajikan judul "Papan Informasi Berbasis Web Server Controlled HTTP Requests di STMIK AUB Surakarta".

\section{METODE PENELITIAN}

\subsection{Metode Pengumpulan Data}

a. Metode Wawancara

Wawancara digunakan sebagai teknik pengumpulan data apabila peneliti ingin melakukan studi pendahuluan untuk menemukan permasalahan yang harus diteliti, tetapi juga apabila peneliti ingin mengetahui hal-hal dari responden yang lebih mendalam. (Sugiyono, 2013). Penulis melakukan wawancara 10 mahasiswa dan dosen pembimbing untuk mengumpulkan informasi dan mengetahui masalah papan informasi elektronik yang ada sehingga dapat menentukan solusi yang tepat atas permasalahan yang ada.

b. Metode Observasi

Observasi peneliti terlibat dengan kegiatan sehari-hari orang yang sedang diamati atau yang digunakan sebagai sumber data penelitian. (Sugiyono, 2013). Penulis melakukan observasi dan mengumpulkan data dengan mengamati secara langsung tentang papan informasi, serta masalah yang diperoleh atau sistem yang sedang berjalan.

c. Metode Studi Pustaka

Tahapan pengumpulan data dengan cara pengumpulan data dengan cara studi pustaka, penulis mencari referensi-referensi yang relevan dengan obyek yang akan diteliti. Pencarian referesnsi dilakukan di perpustakaan toko buku, maupun secara online melalui internet. Setelah mendapatkan referensi - referensi yang relevan tersebut, penulis lalu mencari berbagai informasi yang dapat digunakan dalam penyusunan landasan teori, metodologi penelitian secara

GO INFOTECH: JURNAL ILMIAH STMIK AUB Vol. 25, No. 2, Desember 2019: 143-153 
pengembangan web server secara langsung. Referensi yang dijadikan acuan dapat dilihat di Daftar Pustaka yang terdiri dari jurnal, buku, penelitian dan informasi dari website.

\subsection{Metode Pengembangan Alat}

Prosedur pengembangan yang digunakan pada papan informasi berbasis web server controller http requests ini adalah menggunakan prosedur pengembangan model Waterfall. Model ini melakukan pendekatan secara sistematis dan urut mulai dari level kebutuhan sistem lalu menuju ke tahap analisis, desain, coding, testing atau verification, dan maintenance.

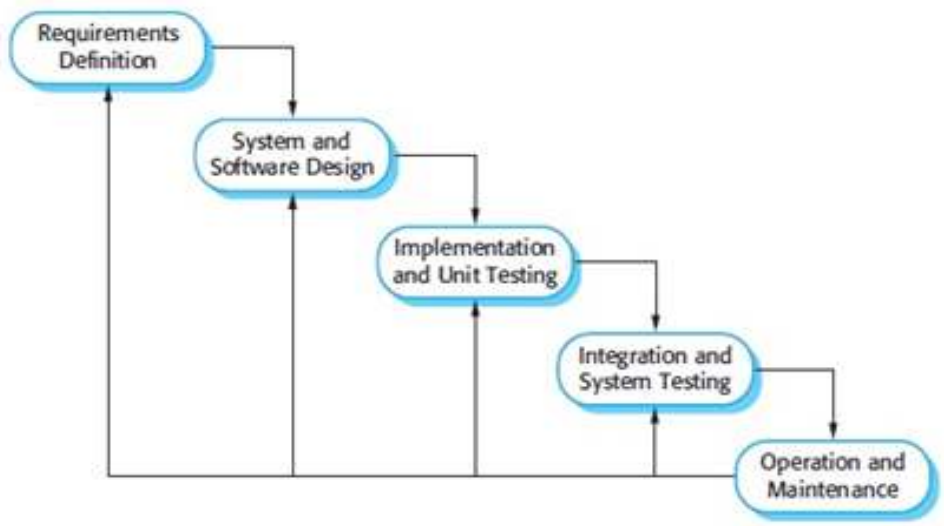

Gambar 1 Siklus Pengembangan Alat dengan metode Waterfall (Pressman, 2010)

Penjelasan gambar 1 dari tahapan-tahapan yang dilakukan didalam metode waterfall:.

a. System And Software Design (Desain alat)

Tahapan ini peneliti melakukan perancangan alat, gambar rangkaian, flowchart terhadap solusi dari permasalahan yang ada di STMIK AUB Surakarta dengan dokumentasi yang dihasilkan dari tahap desain sistem ini menggunakan : Fritzing.

b. Implementation And Unit Testing. (Penulisan Kode Program)

Penulisan program papan informasi berbasis web server controller http request dibuat menggunakan Software Arduino IDE.

c. Integration And Sytem Testing (Pengujian Program dan alat)

Melakukan testing terhadap system dan alat yang telah dibuat kemudian dilakukan pengkajian ulang terhadap sistem dan alat tersebut dan kemudian bisa diperbaiki.

d. Operation And Maintenance.

Tahapan ini bisa dikatakan selesai dalam pembuatan sebuah alat dan sistem. Setelah melakukan analisa, desain dan pengkodean maka sistem dan alat yang sudah jadi akan digunakan oleh user. Dalam tahap ini juga dilakukan pengembangan alat seperti penambahan running text dan fungsi baru dari alat.

e. Requirements definition (Analisis Kebutuhan)

Tahap ini peneliti melakukan analisa data yang diperoleh dari wawancara dengan mahasiswa dan dosen pembimbing yang melihat informasi yang ditampilkan papan informasi eletronik yang ada di depan laboratorium komputer. 


\subsection{Blok Diagram}

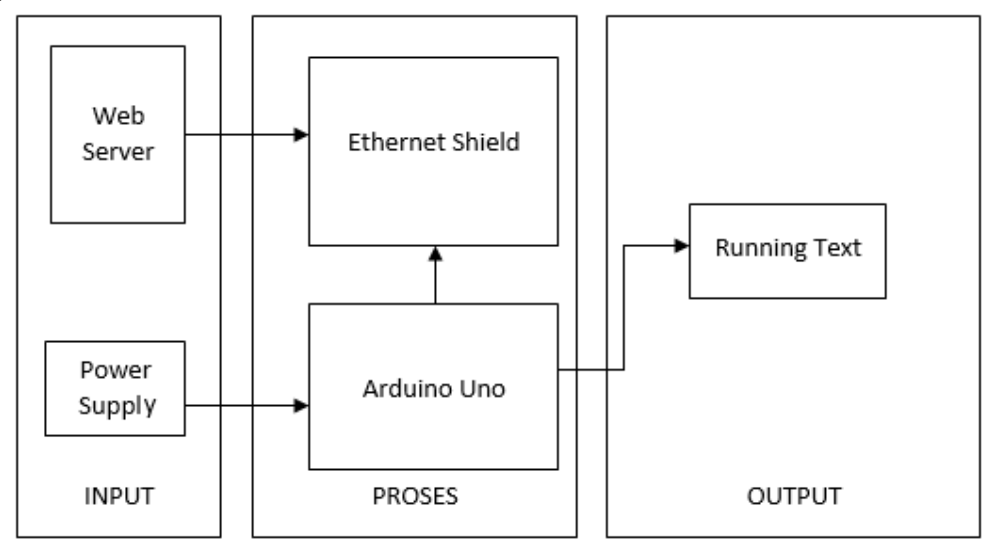

Gambar 2 Blok Diagram

Pada gambar 2 dijelaskan sebagai berikut:

a. Bagian Input

Bagian ini merupakan kumpulan dari beberapa inputan data dari web server ataupun daya yang masuk ke arduino uno dan ethernet shield.

b. Bagian Unit Proses

Bagian ini menggunakan ethernet shield sebagai penghubung ke internet dan arduino uno yang berfungsi sebagai pusat pengolah data atau dapat dikatakan sebagai CPU (Central Processing Unit) yang mana tugasnya mengolah semua data yang masuk dan data yang keluar. Bagian ini akan memeriksa input dari ethernet shield dan meneruskanya ke bagian output.

c. Bagian Output

Bagian ini merupakan bagian keluaran dari unit proses yang kemudian di tampilkan ke running text

2.4 Perancangan Proses

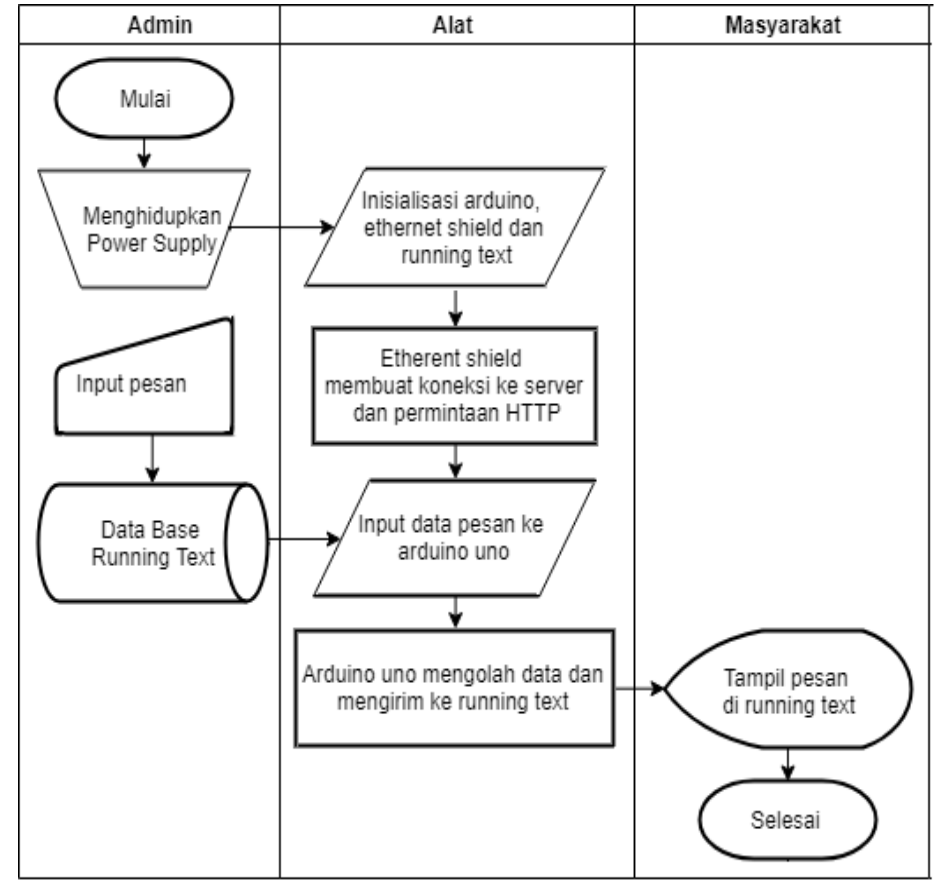

Gambar 3 Diagram Alir Alat

Diagram alir (Flowchart) gambar 3 merupakan gambaran secara grafik yang terdiri dari simbol-simbol dari algoritma-algoritma dalam suatu program yang menyatakan arah alur suatu 
program, diagram alir merupakan dasar dari pemograman. Flowchart perlu dibuat sesuai dengan perangkat keras yang dibuat, agar program yang dibuat terstruktur dan jelas.

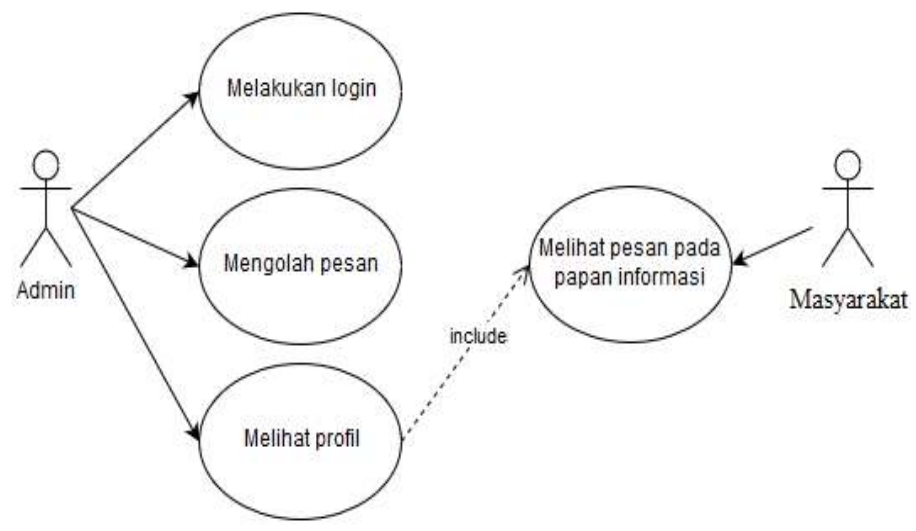

Gambar 4 Usecase Diagram Papan Informasi

Usecase diagram gambar 4 memperlihatkan himpunan usecase dan actor. Usecase diagram sangat penting untuk mengorganisasi dan memodelkan perilaku dari suatu sistem yang dibutuhkan serta diharapkan pengguna. Berikut Usecase Diagram papan informasi berbasis web server controlled http requests di STMIK AUB Surakarta.

\section{HASIL DAN PEMBAHASAN}

\subsection{Pengujian}

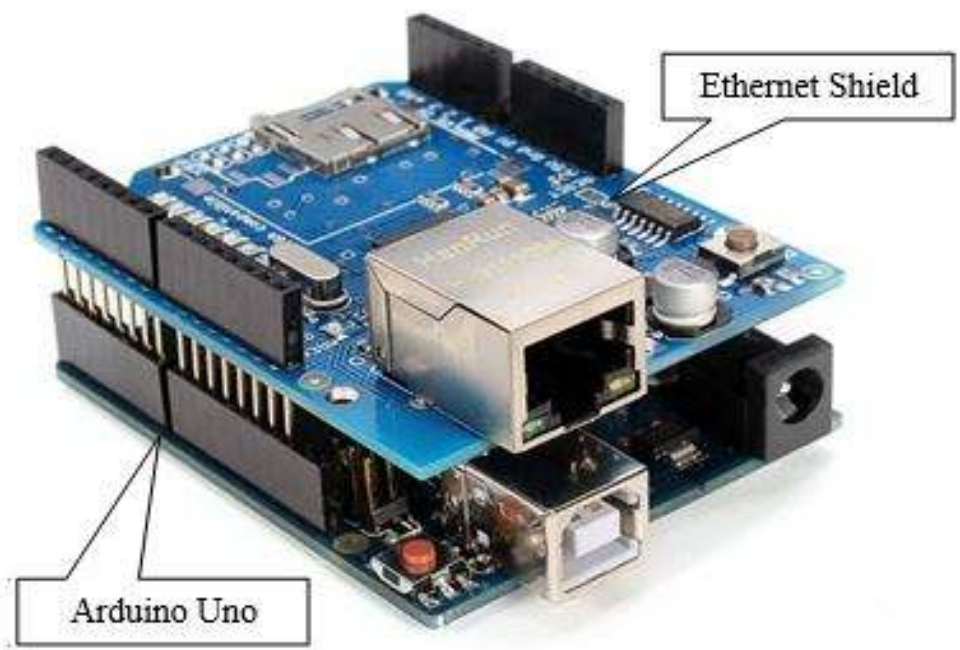

Gambar 5 Pengujian Ethernet Shield

Pengujian ini membutukan arduino uno agar ethernet shield dapat dilakukan pengujian. Dilakukan dengan plug-in module Ethernet Shield ke board arduino seperti pada gambar 5. Agar terhubung ke jaringan internet mengunakan kabel RJ-45. Pengujian ini dilakukan untuk mengetahui apakah Ethernet Shield dapat berfungsi dengan baik atau tidak.

Pengujian rangkaian ini dengan menghubungkan arduino ethernet shield ke komputer. Hubungan modul dengan komputer adalah jenis peer to peer sehingga sambungan yang digunakan adalah cross. Kabel yang digunakan jenis UTP dengan konektor RJ45 yang di cramping crossover untuk menghubungkan localhost komputer dengan Ethernet Shield. Selanjutnya pada IDE Arduino di-upload program yang sudah disiapkan sebelunya. Setelah tersambung dengan komputer dan program telah di-upload langkah selanjutnya adalah dengan mengatur IP komputer disesuaikan dengan IP modul ethernet agar satu jaringan. IP modul

Papan Informasi Berbasis Web Server Controlled HTTP Requests di STMIK AUB Surakarta 
ethernet menggunakan IP 192.168.202.7 sehingga komputer kita set dalam range IP modul ethernet yaitu 192.168.202.1 Tampilan pengaturan IP komputer dapat dilihat pada gambar 6 . dan pengaturan IP arduino pada gambar 7.

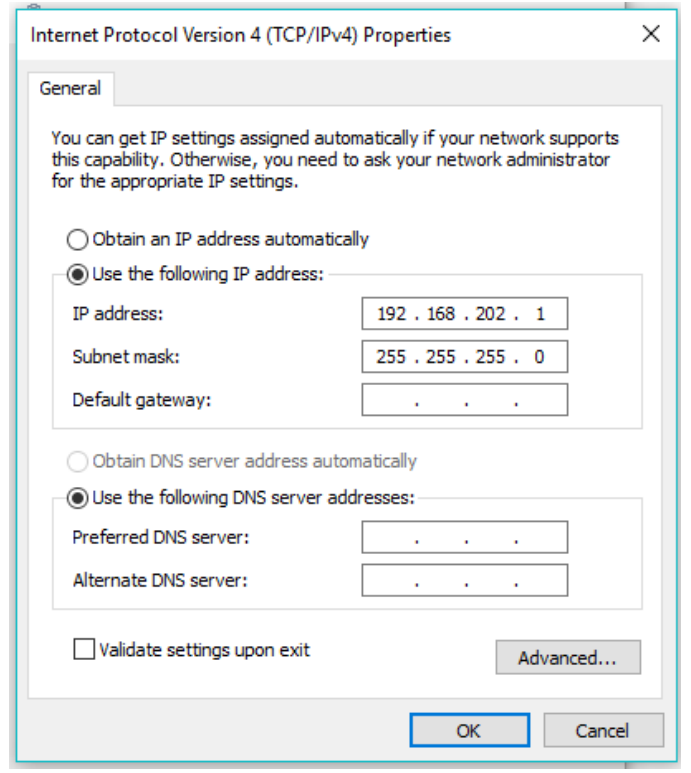

Gambar 6 Pengaturan IP pada komputer

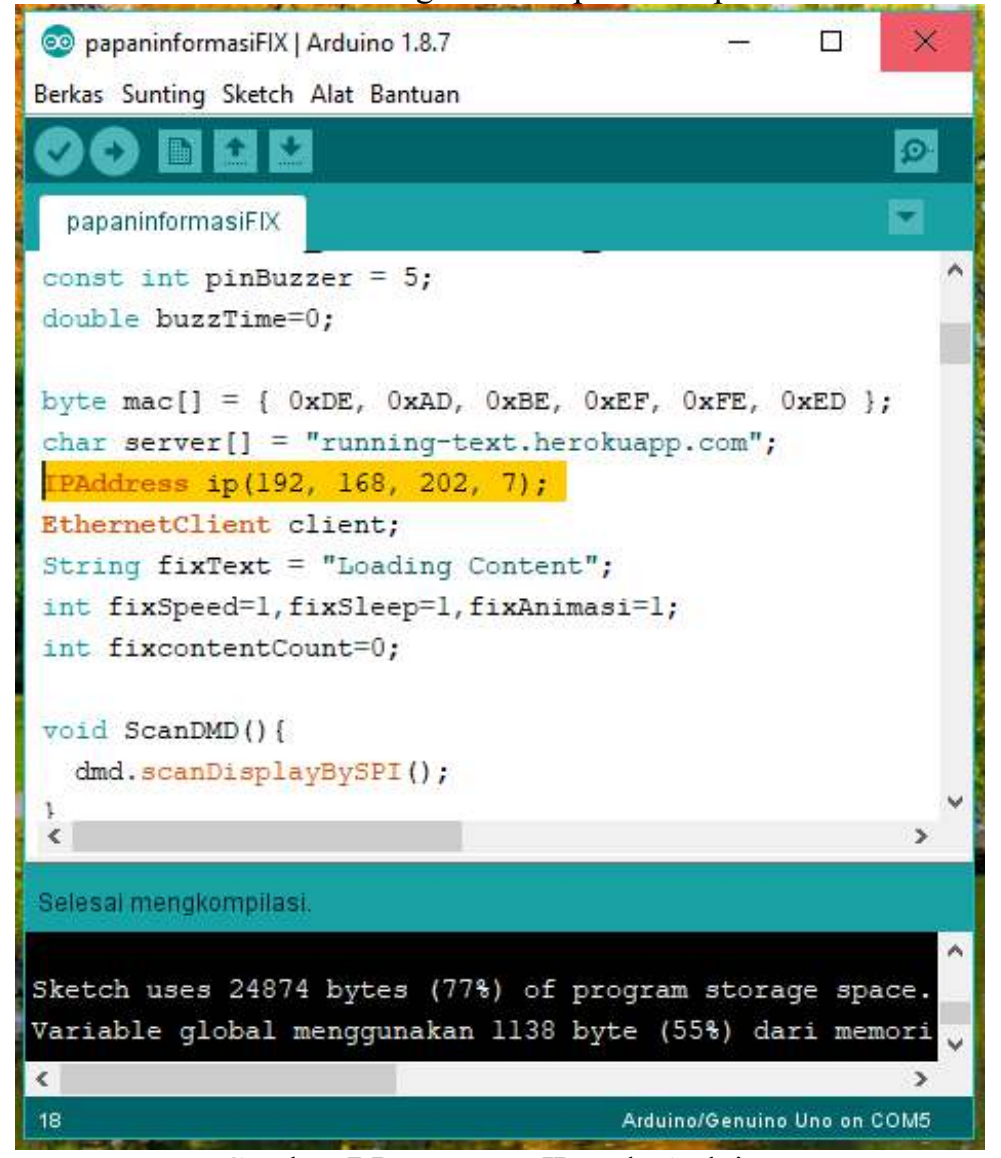

Gambar 7 Pengaturan IP pada Arduino

Pengecekan koneksi antara modul dan komputer dengan menggunakan program DOS 
yaitu dengan instruksi PING, hasil pengecekan komunikasi antara modul IP dapat dilihat pada gambar 8. Dari hasil pengujian dapat dilihat komunikasi antara modul ethernet dan komputer terlihat bagus, dengan ping time $<10 \mathrm{~ms}$ serta $0 \%$ lost.

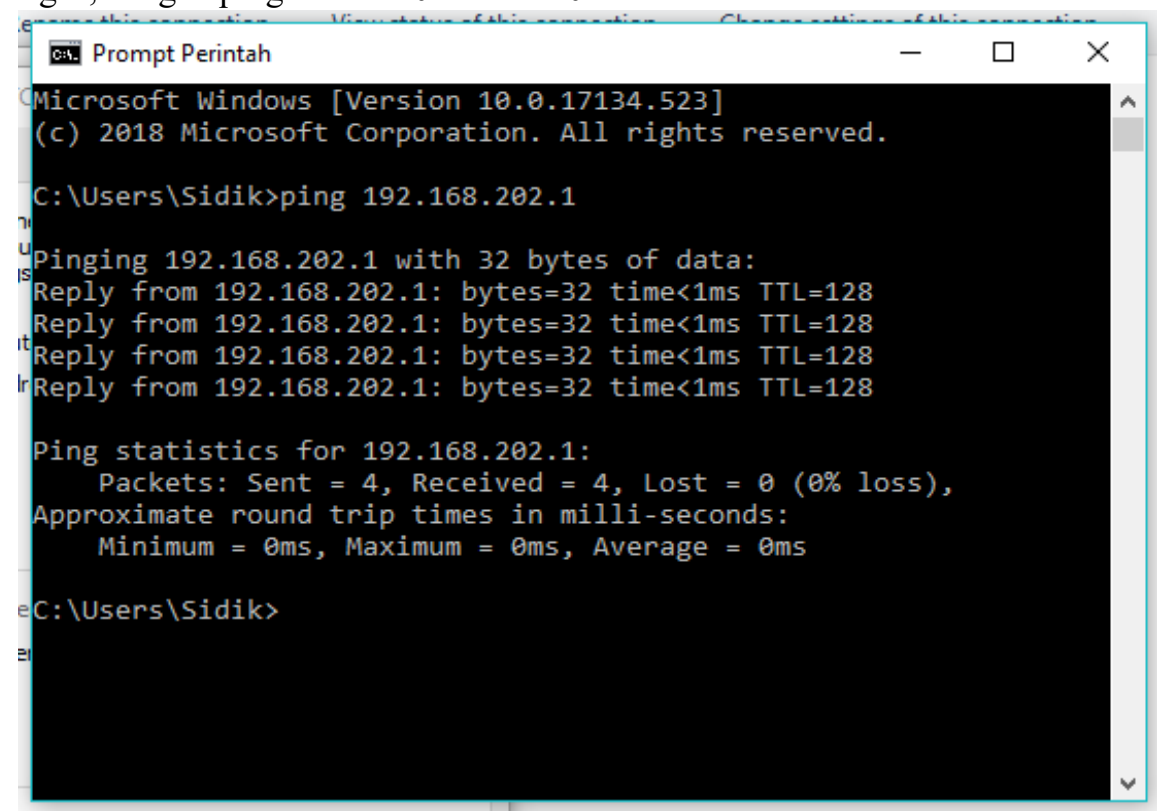

Gambar 8 Pengecekan Komunikasi dengan PING

Pengecekan pengambilan data dan memprosesnya dengan menuliskan informasi di webserver. Pengujian ini dilakukan untuk mengetahui apakah arduino ethernet shield dapat melakukan permintaan ke database dan mengambil informasi yang tersimpan lalu menghasilkan output yang sesuai di database. Jika Arduino ethernet shield bekerja dengan baik maka jika dilihat pada serial monitor IDE Arduino akan tertampil connected, informasi yang berhasil diambil dapaat tampil di serial monitor dan pada titlebar serial monitor terdapat port 5 yang digunakan oleh Arduino seperti pada gambar 9. Hasil dari pengujian ini dapat dilihat pada gambar 9. dari hasil yang di dapat bisa disimpulkan bahwa arduino ethernet shield dapat berkerja dengan baik.

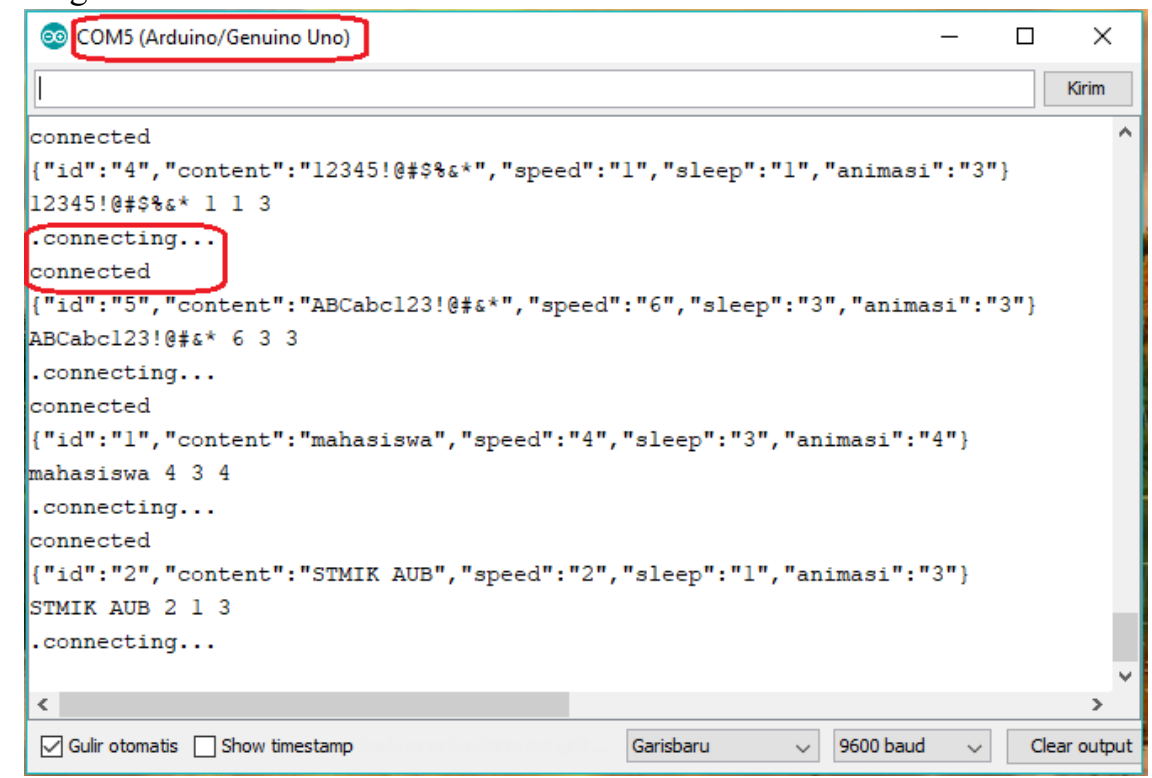

Gambar 9 Serial Monitor Arduino 
Pengujian berikutnya ini bertujuan untuk mengetahui apakah running text dapat menampilkan pesan yang telah di proses oleh Arduino Ethernet Shield dengan baik atau tidak. Menghubungkan pin-pin running text dengan pin Arduino membutuhkan converter karena konektor pada running text tidak bisa langsung di hubungkan ke arduino.

Tabel 1 Hasil Pengujian Running Text

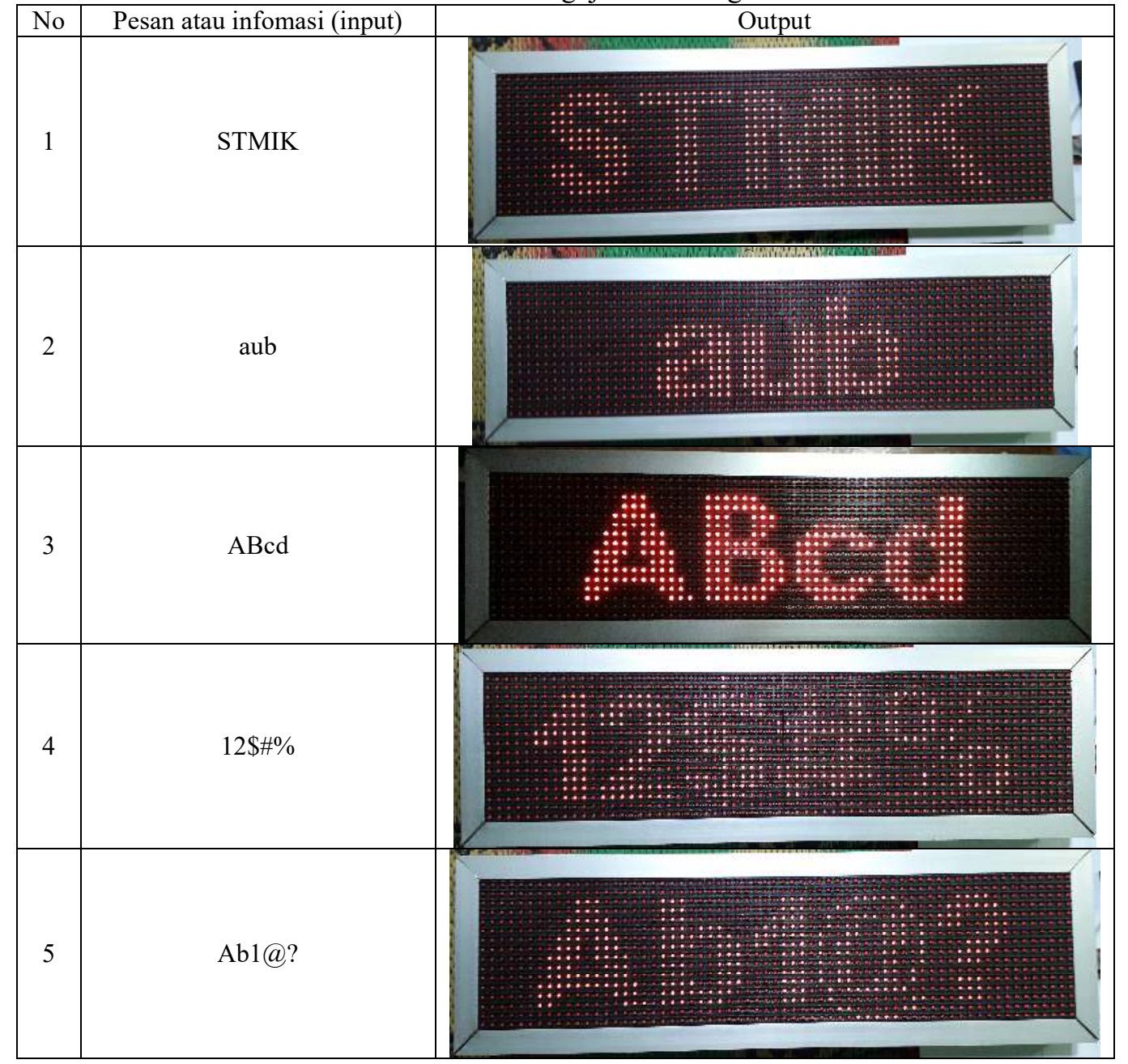

Pengujian pada bagian ini, penulisa menguraikan tentang tahapan-tahapan dalam melakukan pengujian terhadap sistem dan program yang sudah dibuat, sehingga sistem tersebut bebas dari kesalahan agar dapat dilanjutkan pada proses selanjutnya yaitu implementasi sistem dengan menggunakan blackbok testing sebangai metode pengujian sistem.

Tabel 2 Pengujian blackbok testing system

\begin{tabular}{|l|l|l|l|l|}
\hline No & $\begin{array}{l}\text { Komponen Yang } \\
\text { Diuji }\end{array}$ & Data Masukan & $\begin{array}{l}\text { Hasil Yang } \\
\text { Diharapkan }\end{array}$ & Kesimpulan \\
\hline 1 & Halaman login & $\begin{array}{l}\text { Username dan } \\
\text { password salah }\end{array}$ & $\begin{array}{l}\text { Tidak dapat } \\
\text { masuk pada } \\
\text { halaman beranda }\end{array}$ & valid \\
\hline 2 & Halaman profil & Klik menu profil & $\begin{array}{l}\text { Username dan } \\
\text { password benar } \\
\text { masuk pada } \\
\text { halaman beranda } \\
\text { informasi visi dan } \\
\text { misi STMIK } \\
\text { AUB Surakarta }\end{array}$ & $\begin{array}{l}\text { Sistem dapat } \\
\text { Salid }\end{array}$ \\
\hline
\end{tabular}

GO INFOTECH: JURNAL ILMIAH STMIK AUB Vol. 25, No. 2, Desember 2019: 143-153 
Lanjutan Tabel 1 Pengujian blackbok testing system

\begin{tabular}{|l|l|l|l|l|}
\hline No & $\begin{array}{l}\text { Komponen Yang } \\
\text { Diuji }\end{array}$ & Data Masukan & $\begin{array}{l}\text { Hasil Yang } \\
\text { Diharapkan }\end{array}$ & Kesimpulan \\
\hline 4 & Halaman pesan & $\begin{array}{l}\text { Klik menu pesan, } \\
\text { lalu edit data } \\
\text { pesan serta } \\
\text { mengatur animasi, } \\
\text { speed, dan sleep. }\end{array}$ & $\begin{array}{l}\text { Data pesan tampil } \\
\text { dan terupdate. }\end{array}$ & Valid \\
\hline
\end{tabular}

\subsection{Hasil Implementasi}

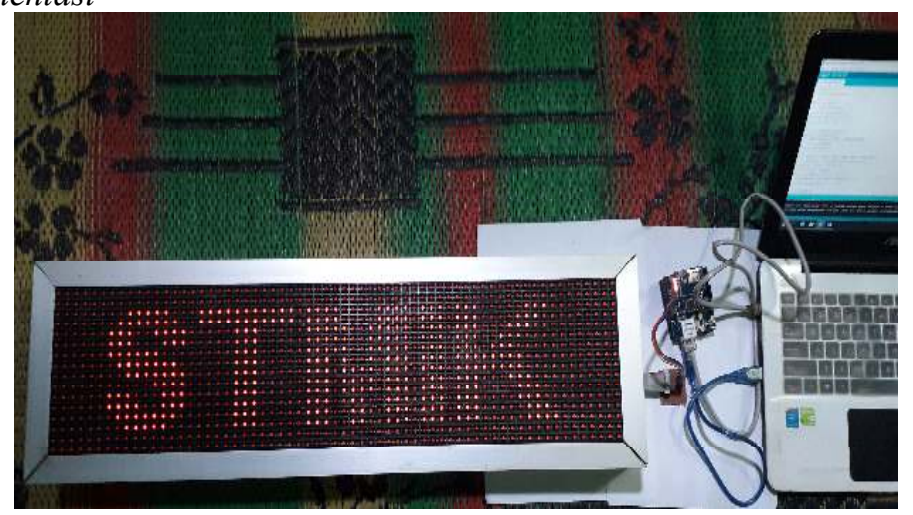

Gambar 10 Rangkaian Keseluruhan Alat

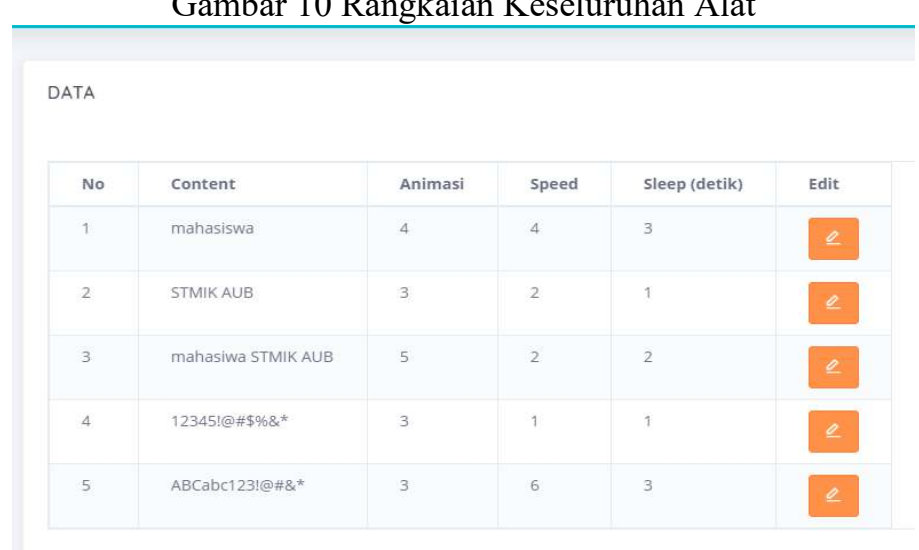

Gambar 11 Tabel Pesan Di Web Server

\subsection{Pembahasan}

Adapun cara penggunaan alat papan informasi ini sebagai berikut:

a. Langkah pertama hubungkan arduino dengan sumber tengan DC seperti pada port usb laptop atau PC dengan menggunkan kabel USB.

b. Langkah selanjudnya hubungkan arduino ethernet shield dengan port ethernet PC atau Laptop menggunakan kabel LAN serta atur ip andress pada PC atau laptop agar arduino ethernet shield mendapatkan jaringan internet

c. Sambungkan conektor ke running text dan converter ke ethernet shield.

d. Selanjudnya buka browser, kemudian pada kotak URL browser masukan link https://running-text.herokuapp.com/ index.php/Main/Profil dan login pada alamat websever jika berhasil akan muncul tampilan halaman profil, arahkan kursor ke menu pesan.

e. Setelah masuk ke halaman pesan akan ada beberapa tabel yang berisi pesan atau informasi untuk mengubahnya, arahkan kursor ke tabel edit, rubah informasi yang ingin di ganti setelah melakukan perubahan, simpan informasi agar tersimpan dan dapat di tampilkan pada running text. 
Setelah alat papan informasi di rangkai dengan benar dan mendapatkan tengangan serta jaringan internet, arduino ethernet shield akan mengambil data yang sudah ada sebelunya dan memperosesnya lalu ditampilkan ke running text. Arduino akan menampilkan semua pesan secara berurutan sesuai yang ada di database.

\section{KESIMPULAN}

Berdasarkan penelitian yang telah dilakukan yaitu Papan Informasi Berbasis Web Server Controlled HTTP Requests di STMIK AUB Surakarta dengan menggunakan arduino UNO, maka dapat diambil kesimpulan sebagai berikut. Running text (P10) yang menjadi papan informasi dengan mengunakan mikrotroler (Arduino) dan webserver telah sesuai dengan yang dirancang. Ethernet Shield sebagai jalur komunikasi arduino pengendali papan informasi dengan webserver untuk merubah informasi yang ditampilkan, sehingga papan informasi dapat di update di mana saja melalu webserver yang telah dibuat. Webserver sebagai tempat admin menginputkan informasi yang akan di tampilkan di running text. Informasi yang dapat disimpan sejumlah lima baris dengan pesan yang berbeda dan animasi tampilan pesan yang berbeda. Running text sebagai ouput informasi dapat menampilkan 80 karakter dengan mengunakan animasi from left dan from right, menampilkan 7 sampai 8 karakter dengan animasi appear, from bottom, from top dan flash.

\section{SARAN}

Sebagai pengembangan lebih lanjut penelitian Papan Informasi Berbasis Web Server Controlled HTTP Requests di STMIK AUB Surakarta, penulis menyarankan board arduino uno sebaiknya di ganti dengan mikrokontroler yang memiliki banyak memori agar dapat memuat banyak perintah perintah yang beragam untuk running text. Diperlukan pengembangan untuk sistem keamanan dan tampilan pada webserver agar lebih menarik tidak hanya warna merah saja. Papan informasi running text menampilkan informasi berupa angka, huruf, dan simbol. Perlu ada pengembangan lebih lanjut seperti dapat menampilkan logo, gambar dan video. Tampilan papan informasi dalam bentuk running text hanya dapat mengunakan satu baris tampilan, diperlukan pengembangan agar dapat menampilkan pesan atau informasi yang lebih banyak dan beragam.

\section{DAFTAR PUSTAKA}

[1] Azrofata, dkk.2015. Purwarupa Running Text Tampilan Informasi Led Matrix Berbasis Arduino Dan Android Di Perpustakaan Unila. Lampung : Lembaga Penelitian dan Pengabdian Universitas Lampung.

[2] Buana, I Komang Setia. 2014. Jago Pemrograman PHP untuk Pemula dan Orang Awaw. Jakarta Timur : Dunia Komputer.

[3] Budiharto dan Rahardi. 2005. Tehnik Reparasi PC dan Monitor. Penerbit: PT Elek Media Komputindo, Jakarta.

[4] Dharmawan. 2017. Mikrokontroller: Konsep Dasar dan Praktis. Penerbit: UB Press, Malang.

[5] Hadi. 2016. Administratif Jaringan Komputer. Penerbit Kencana, Jakarta.

[6] Hin, K. 2007. Pemrograman Mikrokontroler PIC I6F84A. Yogyakarta: Andi Yoyakarta

[7] Jogiyanto. 2005. Analisis dan Desain Sistem Informasi. Yogyakarta : Penerbit Andi.

[8] Kadir. 2017. Pemrograman Arduino dan Processing. Penerbit PT Elek Media Komputindo, Jakarta.

[9] Kadir. 2017. Pemrograman Arduino \& Android Menggunakan App Inventor. Penerbit PT Elek Media Komputindo, Jakarta.

GO INFOTECH: JURNAL ILMIAH STMIK AUB Vol. 25, No. 2, Desember 2019: 143-153 
[10] Marisa. 2016. Web Programming (Client Side and Server Side). Penerbit Deepublish, Yogyakarta.

[11] Munawar. 2005. Pemodelan Visual dengan UML. Yogyakarta : Graha Ilmu.

[12] Munawaroh, 2005. Mengeksplorasi Database PostgreSQL dengan PgAdmin III. Semarang Universitas Stikubank.

[13] Nugroho, Bunafit. 2013. Dasar Pemrograman Web PHP-MySQL dengan Dreamweaver. Yogyakarta : Gava Media.

[14] Pressman, Roger, S. 2010. Software Engineering: A Practitioner's Approach, Fifth Ed. New York, McGraw-Hill Book Company

[15] Rerung. 2018. Pemrograman Web Dasar. Penerbit Deepublish, Yogyakarta.

[16] Rosa AS dan M.Shalahuddin. 2013. Rekayasa Perangkat Lunak Terstruktur Dan Berorientasi Objek. Bandung : INFORMATIKA.

[17] Simanjuntak, Suhendar. 2018. Rancang Bangun Running Text P10 16x32 Berbasis Arduino Uno Dengan Komunikasi SMS (Short Message Service). Jakarta Barat: Universitas Buana Jakarta.

[18] Sugiyono, 2013. Metodelogi Penelitian Kuantitatif, Kualitatif Dan R\&D. Bandung : Alfabeta.

[19] Sulaiman, Arif . 2012. ARDUINO : Mikrocontroller bagi pemula hingga Mahir. https://widuri.raharja.info/index.php/SI11334669938, Skripsi, STMIK Raharja, Tangerang.

[20] Susilo, Deddy. 2009. 48 Jam Kupas Tuntas Mikrokontroler MCS51 \& AVR. Penerbit ANDI OFFSET, Yogyakarta.

[21] Suryadi, Munthe. 2018. Belajar Bahasa Pemrograman C++ Menggunakan Borland C++. Penerbit: Uwais Inspirasi Indonesia, Ponorogo.

[22] Suyanto. 2004. Analisis dan Desain Aplikasi Multimedia untuk Pemasaran. Yogyakarta : Penerbit Andi.

[23] Widodo, Muthohir. 2014. Rancang Bangun Display Jadwal Pada Laboratorium Komputer STMIK AUB Surakarta. Surakarta: STMIK AUB Surakarta.

[24] Wildian, Marnita. 2013. Sistem Penginformasi Keberadaan Orang Di Dalam Ruang Tertutup Dengan Running Text Berbasis Mikrokontroler dan Sensor PIR (Passive Infrared). Padang : Univeristas Andalas.

[25] Zainuri, dkk. 2015. Implementasi Bluetooth HC-05 untuk Memperbarui Informasi Pada Perangkat Running Text Berbasis Android. Malang: Universitas Brawijaya.

[26] www.idschool.net, 20.30 WIB, 7/08/2018

[27] www.penguintutor.com, 20.30 WIB, 7/08/2018

[28] www.robotic-id.org, 22.25 WIB, 05/09/2018.

[29] www.lelong.com.my, 01.20 WIB, 01/12/2018.

[30] https://pccontrol.wordpress.com, 01.30 WIB, 20/11/2018.

[31] https://digiwarestore.com, 01.30 WIB, 23/11/2018. 